\title{
Flexible procedure for concreting in hot and dry climate based on Phase Change Material
}

\author{
Mahmoud HSINO ${ }^{1,{ }^{*}}$ and Jerzy PASLAWSKI ${ }^{2}$ \\ ${ }^{1}$ Stanislaw Staszic University of Applied Sciences in Pila, Politechnic Institute, 64-920 Pila, \\ 10 Podchorazych Str., Poland \\ ${ }^{2}$ Poznan University of Technology, Department of Construction and Environmental \\ Engineering, 60-965 Poznan, 5 Piotrowo Str., Poland
}

\begin{abstract}
The article presents the possibilities of using a flexible approach in designing production processes in construction on an example of concreting in a hot and dry climate. The basic drawback of typical quality management system procedures is their rigidity. It is based on the assumption that building processes are carried out in favorable conditions. Meanwhile, these conditions often change to a large extent during the process, and the accuracy of weather forecasts is limited. The aim of the article is to demonstrate the advantages of flexibility procedures for concreting on the example of concrete modification with phase-change materials. The conducted research has shown a reduction in the risk of structure damage during maturing of young concrete due to the use of hybrid phase-change materials in the conditions of central Syria climate. Phase-change materials provide lowering of the thermal peak in the initial maturation period and unification of the temperature in the cross-section of the element (limitation of the thermal gradient). At the same time, PCM's slightly reduce the compressive / tensile strength of the concrete. As a result, this reduces the risk of cracking of the concrete element, which is the basis for ensuring greater durability of the element and a longer life cycle of the building.
\end{abstract}

\section{Introduction}

Building Construction due to its specificity is characterized by a significant difference in relation to other sectors of economy. Important factors related to the specificity of construction include:

- Immovability of the product

- Unstable production conditions

- Relatively high unit cost of the product

\footnotetext{
*Corresponding author: $\underline{\mathrm{m}-\mathrm{h} \operatorname{sino} @, 02 . p 1}$
} 
- Problems with maintaining permanent staff

- Seasonality in construction output

- Sensitivity of production to changing environment

The last two features are related to the dependence on the impact of the season. In the case of seasonality, the dependence on budget restrictions is often emphasized (usually at the beginning of the year, while at the end of the year the necessity of hastily money spending is taken into account). In turn, the second feature is related to the sensitivity of weather factors, which can lead to the extreme necessity of demolition of the concrete element and re-work. Naturally, various reasons should be taken into account when analyzing the causes of problems in the implementation of construction processes. They can primarily be classified into two categories: related to construction and resulting from the impact of the broadly understood building environment (environmental, socio-political or legal factors). The factors directly related to construction include: rising costs of salary, materials and supplies, delays or inflation, lack of qualified employees, errors in project documentation, lack of due supervision, untimely deliveries and implementation of processes in uncontrolled conditions (significant impact of weather and other external factors ). The proper implementation of health and safety regulations is also associated with the correct course of construction works. The involved construction manager, thanks to proper communication between all participants of the construction process, prevents conflicts and achieves harmonious cooperation. Achieving success requires efficient risk management, taking into account many potential sources. From this perspective, the manager's support in weather risk management in concreting can be an important element guaranteeing compliance with the requirements regarding costs, time of completion and quality.

The article focuses on procedures related to the concreting process under hot and dry climate conditions, which means weather risk management in countries where high temperature, low humidity and high wind speed pose a threat to the correct construction of the concrete structure.

Weather factors have an impact on the construction industry due to the implementation of processes in a large part on the construction site. Weather risks occur outside of construction also in other sectors of the economy, such as energy (electricity demand dependent on weather) or agriculture (risk of reduced yields as a result of drought or frost).

In construction, quality management systems are often based on too rigid procedures that do not take the variability of the environment into account. As a rule, it is assumed that the processes are carried out under favorable conditions, with some restrictions on their use. For example, $13^{\circ} \mathrm{C}$ [1] is considered the optimum temperature for concreting and maturing. On the other hand, the borderline upper limit of ambient temperature for concreting is often assumed at $29-32^{\circ} \mathrm{C}$. Formularizing such restrictions seems to be debatable, because the temperature of concrete is of key importance. Situations when it becomes necessary to repair a damaged element of critical infrastructure can be easily imagined (runway at the airport, bridge, drainage ditch, road, etc.). Quality management system procedures should also take into account unusual conditions when concreting is allowed under special conditions. An example is the use of phase-change materials that allow to exceed typical technological barriers due to unique properties [2, 3]. Another example of innovative solution for concreting under hot climatic conditions is the use of superabsorbing polymers [4] or manioc based retardants [5]. 
The aim of the article is to present the beneficial effects of the use of phasechange materials in concreting in hot and dry climates, when the ambient temperature reaches $45^{\circ} \mathrm{C}$, and the daily temperature amplitude is $30^{\circ} \mathrm{C}$.

The graph below (Fig. 1) of the maximum and minimum monthly air temperature in Damascus indicates the existence of significant differences between them (e.g. $35^{\circ} \mathrm{C}$ in July).

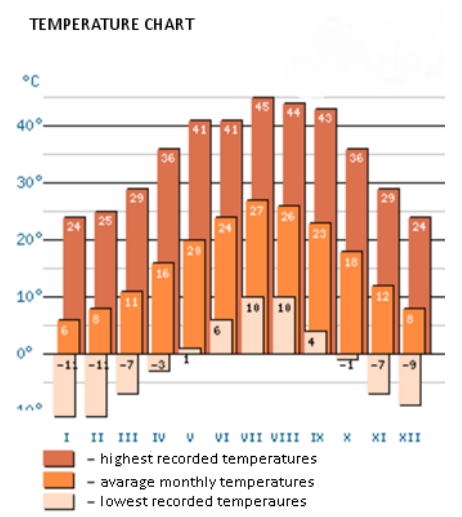

Fig.1. Maximum and minimum monthly temperatures in Damascus [6]

After this introduction, the basic principles of concreting in these unfavorable conditions were presented, and then the basic possibilities of using the technological flexibility were indicated. Later, the research procedure is described in a specially constructed climatic chamber, which enabled the preparation and testing of three concrete mix recipes. The research results and conclusions are subsequently presented.

\section{Problem definition}

A view is often found that concreting at elevated ambient temperature in the initial period has a positive effect on early concrete strength and does not cause adverse effects at a later time. However, as shown in the detailed initial studies, fast cement hydration contributes to a weaker concrete (more porous) microstructure. This hypothesis is confirmed not only in strength development tests (the initial high dynamics of compressive strength build-up is significantly slowed down [7]), but above all in a negative impact on the durability of concrete $[8,9]$. The cause of these unfavorable phenomena is the fact that at a high initial rate of hydration there is too little time for ion diffusion outside the layer of hydration products directly surrounding the cement grains. This limits the homogeneous loss of hydration products in the space between the grains, which occurs at a lower temperature [10]. The basic problem in these maturation conditions is the risk of exceeding the tensile strength of the concrete by thermal stresses in freshly-cured concrete. Phase-change materials enable the reduction of the thermal peak in the initial period of maturation occurring due to the exothermic reaction dynamized by the high temperature of the environment and provide a more even temperature distribution in the cross-section of the ripening element (reduction of the thermal gradient). The possibilities of using 
phase change materials for this purpose were indicated by Bentz and Trupin [11]. The simulation tests carried out by Arora et al. confirmed the validity of these assumptions [12] and laboratory tests. Savija [13] showed the benefits of using phase change materials also during operation (lower maintenance costs of infrastructure facilities - e.g. bridges).

\section{Hot weather concreting procedure}

Principles of laying concrete in high temperature can be included in the following 10 points $[1,14]$ :

1. Ensuring adequate possibilities of collection, laying and care of concrete at the construction site

2. Using larger aggregate fractions

3. Not laying concrete in the afternoon or directly in the afternoon

4. Planning to deliver a concrete mix taking into account its reduced temperature (adding ice, spraying the aggregate with water, etc.)

5. Agreeing with the designer of the construction of expansion joints (more often than at a lower temperature)

6. Using canopies and wind shields to reduce potential problems resulting from direct sunlight or increase evaporation of concrete water due to wind

7. Applying the appropriate implementation schedule - for example, concreting the floor after making the walls and roof

8. Application of measures to limit evaporation

9. Using ice as part of the water dispensed into the concrete mix or liquid nitrogen to remove the concrete components

10. Moistening the substrate before concreting.

Proper curing of the fresh concrete plays a key role.

In Fig. 2 different concrete curing methods are listed, also considering the use of phase-change material as an internal thermal effect.

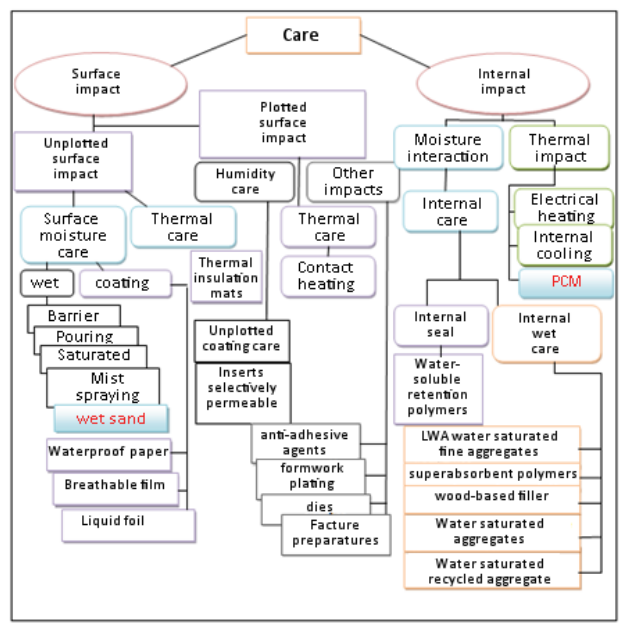

Fig. 2. Different curing procedures including phase change material (PCM) based on [15]. 
From the point of view of this study, the methods of cooling the concrete components, the use of retarding additives, the use of cement with low dynamics of hydration heat release, and in the scope of care methods:

- In the case of an unclosed surface - the use of concrete preservatives in the form of a protective film on the surface of freshly poured concrete (the main advantage is the possibility of applying on large surfaces practically immediately after laying the concrete mix) or applying a layer of damp sand on the concrete surface providing periodic wetting with water (if the surface is horizontal)

- In the case of a decorated surface - the use of external shields to prevent evaporation of water from the concrete surface

- The use of phase change materials as an internal curing option (possible in both cases for the care of the unclosed and closed surfaces). The aim of the research was to compare the risk of damage to the concrete structure in the initial maturation phase based on the determination of the cracking risk coefficient:

$$
\mathrm{Cr}=\Delta \mathrm{T} / \mathrm{fc}
$$

where: $\mathrm{Cr}$ - Cracking risk coefficient $\Delta \mathrm{T}$ - temperature gradient $\left[{ }^{\circ} \mathrm{C}\right] \mathrm{fc}$ compressive strength of concrete [MPa]. Naturally more precise risk of concrete cracking can be determined by following thermal stress and tensile strength. The present research was aimed at confirming the use of hybrid phase change materials and optional modification with a retarder.

\section{Laboratory tests using phase change materials .}

In order to carry out the experiments, a climatic chamber was built, which allows testing different concrete mix in hot climates. The aim of the research is to determine the effect of PCM - (Phase Change Materials) on the reduction of thermal gradients inside a concrete slab in the initial maturing phase. The chart below presents the daily cycle of temperature and humidity (from 20:00 to 20:00 the next day), prevailing in hot and dry climate (Hama - Syria).

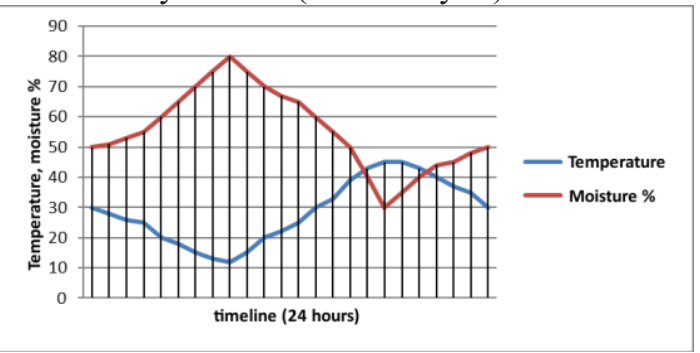

Fig. 3. Diurnal course of temperature and humidity cycle in the summer, in Hama:(source: own)

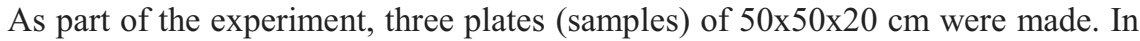
this experiment, i.e. a hybrid solution was used, namely two different phase change materials (PCM) and a retarder were used.

- The first plate is composed of concrete mix with two PCM materials and a retarder, in short - RET 
- The second plate is composed of concrete without any additions (witness), in short

- NOR

- Third plate is composed of concrete with the addition of two PCM materials, in short 2 PC

The first material (PCM) has following characteristics:

- Phase transition temperature of $23 \div 26^{\circ} \mathrm{C}$

- Thermal capacity $142 \mathrm{~kJ} / \mathrm{kg}$

- Addition rate of $2.4 \%$ in relation to cement dose

The second one is characterized by:

- Phase transition temperature from $29^{\circ} \mathrm{C}$ to $36^{\circ} \mathrm{C}$

- Heat storage capacity $160[\mathrm{~kJ} / \mathrm{kg}]$

- Addition rate of $2.4 \%$ in relation to cement dose

Table 1 presents the recipe of the plate components - RET, concrete class C 30/37, consistency S4.

Table 1. The composition of the concrete slab mixture - RET

\begin{tabular}{|l|l|l|l|}
\hline Material name & Supply source & $\begin{array}{l}\text { The amount of kg per 1 } \\
\mathbf{m}^{\mathbf{3}} \text { of compacted } \\
\text { concrete }\end{array}$ & $\begin{array}{l}\text { Density } \\
\mathbf{k g} / \mathbf{m}^{\mathbf{3}}\end{array}$ \\
\hline CEM II B-V 42,5N & Warta & 21,56 & 3,1 \\
\hline Plain sand 0/2 & Dabrowa & 54 & 2,65 \\
\hline Gravel 2/8 & Dabrowa & 28,125 & 2,65 \\
\hline Gravel 8/16 & Dabrowa & 28,125 & 2,65 \\
\hline Retarder FL & SIKA & 0,151 & \\
\hline Plasticizer Plastiment BV IM & SIKA & 0,129 & \\
\hline Water & Water supply & 12,27 & \\
\hline PCM -1 & & 0,518 & \\
\hline PCM- 2 & & 0,518 & \\
\hline
\end{tabular}

Table 2 presents the recipe of the plate components - NOR, concrete class C 30/37, consistency S4.

Table 2. The composition of the concrete slab mixture - NOR

\begin{tabular}{|l|l|l|l|}
\hline Material name & Supply source & $\begin{array}{l}\text { The amount of kg per 1 } \\
\mathbf{m}^{\mathbf{3}} \text { of compacted } \\
\text { concrete }\end{array}$ & $\begin{array}{l}\text { Density } \\
\mathbf{k g} / \mathbf{m}^{3}\end{array}$ \\
\hline CEM II B-V 42,5N & Warta & 21,56 & 3,1 \\
\hline Plain sand 0/2 & Dabrowa & 56,25 & 2,65 \\
\hline Gravel 2/8 & Dabrowa & 28,125 & 2,65 \\
\hline Gravel 8/16 & Dabrowa & 28,125 & 2,65 \\
\hline Retarder FL & SIKA & & \\
\hline Plasticizer Plastiment BV IM & SIKA & 0,129 & \\
\hline Water & Water supply & 12,94 & \\
\hline
\end{tabular}

Table 3 presents the recipe of the plate components - 2 PC, concrete class C30/37, consistency S4. 
Table 3. The composition of the concrete slab mixture -2 PC

\begin{tabular}{|c|c|c|c|}
\hline Material name & Supply source & $\begin{array}{l}\text { The ammount of } \mathrm{kg} \\
\text { per } 1 \mathrm{~m}^{3} \text { of compacted } \\
\text { concrete }\end{array}$ & Densitykg/m \\
\hline CEM II B-V $42,5 \mathrm{~N}$ & Warta & 21,56 & 3,1 \\
\hline Plain sand $0 / 2$ & Dabrowa & 54 & 2,65 \\
\hline Gravel 2/8 & Dabrowa & 28,125 & 2,65 \\
\hline Gravel 8/16 & Dabrowa & 28,125 & 2,65 \\
\hline Retarder FL & SIKA & & \\
\hline Plasticizer Plastiment BV IM & SIKA & 0,129 & \\
\hline Water & Water supply & 12,42 & \\
\hline PCM -1 & & 0,518 & \\
\hline PCM- 2 & & 0,518 & \\
\hline
\end{tabular}

\section{Results}

The graphs of temperature waveforms in individual plates are presented below.

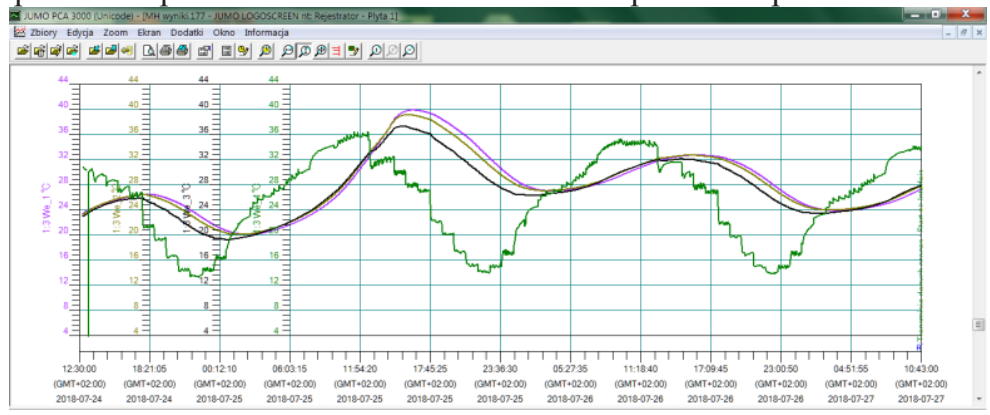

Fig.4 . The temperature course in the RET plate (source: own)

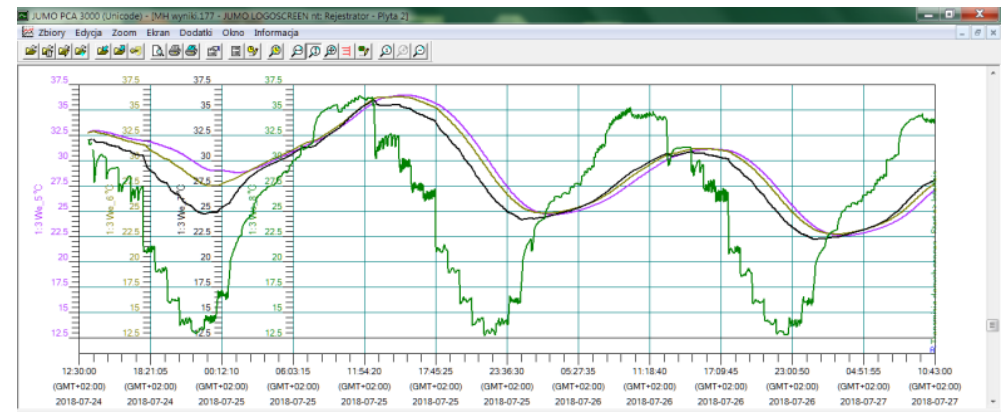

Fig.5. The temperature course in the NOR plate (source: own) 


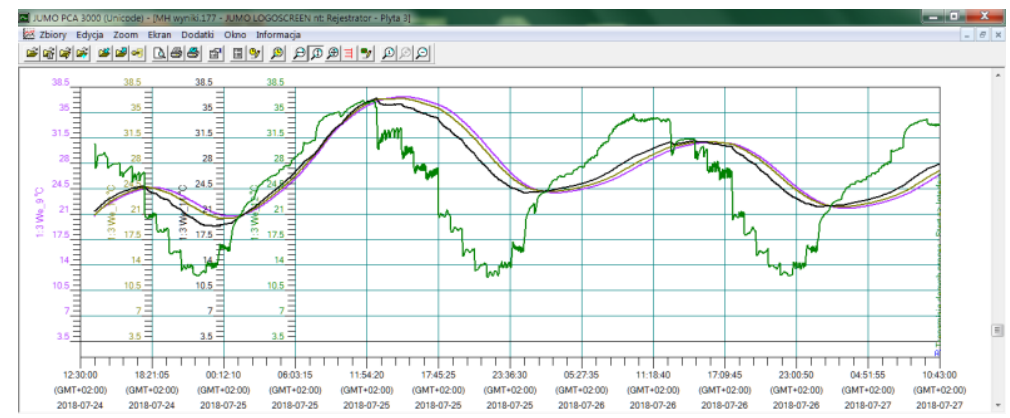

Fig.6. The temperature course in the NOR plate (source: own)

At the same time, from the same concrete mix from which the plate was made, 3 cubes for each mix of $15 \times 15 \times 15 \mathrm{~cm}$ were made. These cubes were made to check the course of compressive strength over time and to determine the risk of cracking of the concrete structure in individual plates in the initial period of maturing.

Based on the obtained results, it can be noticed that the risk of cracking the concrete structure in a board without additives (NOR) is almost one and a half times higher than in panels where phase-change materials (2PC) were added.

The following results are obtained on the basis of the first (1) calculation.

$$
\begin{aligned}
& C_{r}{ }^{R E T}=\frac{2,7}{0,2}=13,5 \\
& C_{r}{ }^{2 P C}=\frac{2,5}{3,25}=0,77 \\
& C_{r}{ }^{N O R}=\frac{4,3}{4}=1,08
\end{aligned}
$$

The obtained results confirm a slow increase in compressive strength in the slabs with the addition of PCM, which means that the structure of the mature concrete will not be defected, as mentioned at the beginning of the article.

All slabs were placed on the same height to eliminate difference in temperature between the individual boards.

Photo number 7. Presents the view of samples in the climatic chamber

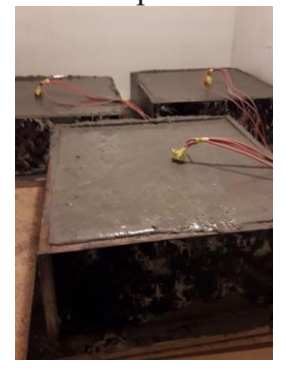

Fig 7. View of samples in the chamber 


\section{Conclusions}

This research and theoretical considerations allow to draw the following conclusions:

1. Phase-change materials used for modification of cement concrete allow to overcome typical technological barriers in the case of concreting in unfavorable conditions (hot and dry climate)

2. It is justified to apply technological flexibility in the form of several curing options depending on the conditions of concreting and maturing, technological capabilities of the plant and the type of concrete element

3. The use of PCM as a cement concrete modifier allows limiting the size of the thermal peak and unification of the temperature in the section of the concrete element, which leads to a reduction in the risk of cracking (which may disqualify concrete element)

4. The addition of PCM to concrete also limits the amount of temperature changes during the operation of the concrete element, which may lead to increased durability and extension of the life cycle of the concrete element

5. The conducted research shows that the use of hybrid solutions based on two phase-change materials reduces the risk of cracking of the concrete structure during its maturation process.

Further research will aim at building a simulation model with experimental verification.

\section{Acknowledgements}

The authors wish to thank for finance support from the Institute of Building Structures at Poznan University of Technology allowing to perform laboratory tests as part of the statutory activities.

\section{Reference}

1. A. M. Neville, Wlasciwosci betonu (Krakow, 2012)

2. A. Y. Benjamin, F. Gabriel, S. Zhenyu, M. T. Alexander, W. Zhenhua, N. Narayanan, S. Gaurav, L. Pilon, Const. and Build. Mat. 147, 466-477 (2017)

3. H. Ahmed, A. A. Khaled, A. Hamza, R. Yasir, A. Shaimaa, Eff. of PCM Int. Conc. B1. H. G. Prev. H. Clim. 8, 1009 (2016)

4. M. Hasholt et al. Const. Build. Mater. 31, 226-230 (2012)

5. G. R. Otoko. Eur. Intern. J. Sci. Tech. 3, 2 (2014)

6. www.transazja.pl

7. R.G. Burg, The Influence of Casting and Curing Temperaure on the Properties of Fresh and Hardened Concrete, (Portland Cement Association 1996)

8. O. Idowu, L. Black, Mag. Conc. Res. 70, 633-647 (2018)

9. N. Gowripalan, J. Cabrera, A. Cusens, P. Wainwright, Conc. Inern. 12, 47-54 (1990)

10. M. Hsino, J. Paslawski. Izol. 2, 46-49 (2014) 
11. D. P. Bentz, R. Trupin, Cem. Conc. Comp. 29, 527-532 (2007)

12. A. Arora, G. Sant, N. Neithalath, Cem. Conc. Comp, 81, 11- 24 (2017)

13. B. Savija, Mat. 11, 654 (2018)

14. ACI 305R-10, Guide to Hot Weather Concreting (American Concrete Institute, 2010)

15. P. Woyciechowski, W. Jackiewicz- Rek, Materialy Budowlane, 5, 44-48 (2012) 